\title{
REGULACIÓN CONSTITUCIONAL DE LA PARTICIPACIÓN DE LOS TRABAJADORES EN LA ECONOMÍA Y EN LA EMPRESA
}

ANTONIO COLOMER VIADEL 


\section{SUMARIO}

NOTA PRELIMINAR. 1. INTRODUCCIÓN. 2. LA CONSTITUCIÓN ECONÓMICA. A. La participación en la Seguridad Social y en otros órganos sobre calidad de la vida y bienestar general. B. La participación en la empresa y su dimensión comunitaria. C. Cooperativas. D. El Acceso de los Trabajadores a la Propiedad de los Medios de Producción. La Economía de Participación y la Economía Social y Solidaria. 


\title{
REGULACIÓN CONSTITUCIONAL DE LA PARTICIPACIÓN DE LOS TRABAJADORES EN LA ECONOMÍA Y EN LA EMPRESA
}

\author{
ANTONIO COLOMER VIADEL* \\ Catedrático de Derecho Constitucional (j) \\ Universidad Politécnica de Valencia \\ Director del Instituto Intercultural para la Autogestión y la Acción Comunal \\ (INAUCO)
}

\section{NOTA PRELIMINAR}

En el texto de la Constitución española de 1978, que cumple 40 años, parece apostarse decididamente por un modelo participativo que alcanza desde las definiciones preliminares de sus artículos siete y nueve hasta el título séptimo de economía y hacienda y en particular el artículo 129 que parece anunciar un verdadero programa revolucionario en relación con la economía y la empresa y el acceso de los trabajadores a la propiedad. Se han creado algunas fórmulas innovadoras pero en general debe decirse que no ha existido la voluntad política de desarrollar toda la potencialidad que existía en el articulado constitucional e incluso que se ha disminuido la tendencia participativa, especialmente en el campo social y económico.

\section{INTRODUCCIÓN}

El modelo constitucional del texto de 1978 en España introduce innovación en varios campos, como la estructura territorial del Estado, pero un aspecto que

* Prof. Dr. Antonio Colomer Viadel. FADE Universidad Politécnica de Valencia. Camino de Vera, s/n 46022 Valencia (España) E-mail: ancovia@urb.upv.es 
llama la atención desde sus primeros artículos es el que responde a un modelo participativo de los ciudadanos, no solo en el campo político sino también en el social, cultural y económico.

En este sentido no puede ser más rotunda la redacción del artículo 9.2, que cierra el título preliminar de la Constitución:

"Corresponde a los poderes públicos promover las condiciones para que la libertad y la igualdad del individuo y de los grupos que se integran sean reales y efectivas; remover los obstáculos que impidan o dificulten su plenitud y facilitar la participación de todo los ciudadanos en la vida política, económica, cultural y social.»

Debemos recordar que en este título preliminar se encuentra la formula política de la Constitución, sus valores y principios y que la trascendencia de su contenido ha hecho que se le proteja de una modificación mediante el procedimiento agravado de reforma que hace equivalente la de cualquiera de sus artículos a la de una reforma total de la Constitución, de acuerdo con el artículo 168 del texto Constitucional.

El sistema participativo se considera un instrumento de integración y por ello se vincula este modelo participativo a la creación, entre otras Instituciones, del Consejo Económico y Social, que para la elaboración de las grandes líneas económicas y los proyecto de planificación del gobierno, debe colaborar y asesorar mediante la intervención de los sindicatos y otras organizaciones de carácter profesional, empresarial y económico.

Este Consejo es un instrumento de participación que hay que situar con carácter general en el mandato constitucional del artículo 9.2, y plasmado en el artículo 131 punto 2, que prevé la creación del Consejo, lo que se hizo por la Ley 21/1991, de 17 de junio. De acuerdo con el modelo participativo de la Constitución, el Consejo debería facilitar las negociaciones de las fuerzas e instituciones presentes en su seno a fin de permitir una participación más decisiva de las mismas, y por tanto, un mayor consenso social y político en la elaboración del plan y en su fase de ejecución ${ }^{1}$.

Desgraciadamente esta potencialidad participativa no se ha cumplido en el caso de tal institución, ni tampoco en otros desarrollos legislativos del modelo participativo.

A lo largo del texto Constitucional, este mandato participativo se reitera y confirma. El artículo 23, en el Título primero, sobre los Derechos y Deberes Fundamentales, señala que «los ciudadanos tienen derecho a participar en los

${ }^{1}$ Colomer Viadel, Antonio (2006), Constitución, Estado y Democracia en el siglo XXI, Edit. UPV, Valencia, pp. 323-325. 
asuntos públicos, directamente o por medio de representantes, libremente elegidos en elecciones periódicas por sufragio universal».

En el capítulo III de este título 1, que trata de los principios rectores de la política social y económica, y en su artículo 48 se indica que «los poderes públicos promoverán las condiciones para la participación libre y eficaz de la juventud en el desarrollo político, social, económico y cultural». Una respuesta a este mandato es la regulación legislativa del voluntariado, según la Ley 6/1996, modificada por la Ley 23/1998. Y en general, el apoyo a las ONGs y sus distintas modalidades de cooperación y asistencia social.

En relación con estos principios rectores de la política social y económica, es importante la garantía establecida en el artículo 53.3 que señala que «el reconocimiento, el respeto y la protección de los principios reconocidos en el capítulo III, informarán la legislación positiva, la práctica judicial y la actuación de los poderes públicos. Sólo podrán ser alegados ante la jurisdicción ordinaria de acuerdo con lo que dispongan las leyes que los desarrolle». De ello se desprende que es preciso ese desarrollo normativo para aplicar estos principios del capítulo III, del título I de la Constitución, es decir, que tienen un cierto carácter programático y no pueden aplicarse directamente desde la Constitución, a diferencia de lo que ocurre con el principio de Igualdad (artículo 14 de la CE). Ahora bien, tales principios no pueden desconocerse en el momento del proceso legislativo, en la aplicación de las normas por los jueces y, en general, en todas las actuaciones de los poderes públicos, y en este sentido suponen un límite cuya contradicción implicaría actos inconstitucionales. Por tanto, de forma transversal ese principio de participación que inspira a toda la Constitución y que se refleja en los principios citados de este capítulo, va a tener su proyección en la llamada Constitución económica.

\section{LA CONSTITUCIÓN ECONÓMICA}

A lo largo y ancho de la Constitución hay múltiples disposiciones que afectan a la vida económica pero los constituyentes elaboraron un título VII sobre Economía y Hacienda que es en el que se centra las disposiciones fundamentales de la que llamamos Constitución económica. Estas disposiciones parten de una función social de la propiedad y de una subordinación de la riqueza al interés general, que se refleja en la participación en la seguridad social, la participación en la empresa desde una concepción comunitaria de la misma y una verdadera promoción de la economía social y solidaria en la que se otorga un especial relieve a las cooperativas y se culmina con un mandato para que los poderes públicos 
faciliten a los trabajadores el acceso a la propiedad de los medios de producción. Este acceso puede realizarse mediante distintas fórmulas y modelos pero tiene una vocación expansiva que debiera culminar en la formalización de un verdadero sector de economía social y solidaria.

Si las disposiciones de este título VII se hubieran incluido en el Título Preliminar o en el título I, evidentemente, hubieran condicionado a todo el sistema constitucional, pero, en todo caso, es un mandato constitucional claro y preciso, que los poderes públicos no pueden desconocer.

Se ha querido criticar esta tendencia social y comunitaria de la economía, pretendiendo que supone la existencia de un riesgo de economía colectivista que chocaría con otros principios económicos también reflejados en la Constitución, como es el reconocimiento del derecho a la propiedad privada y a la herencia (artículo 33), la libertad de empresa en el marco de la economía de mercado (artículo 38), etc. Es cierto que, la función social de estos derechos y de la propiedad y la riqueza puede delimitar su contenido y justificar por utilidad pública formas de expropiación mediante la correspondiente indemnización.

El inicio del artículo 128 que abre el título VII de Economía y Hacienda, no puede ser más rotundo: «toda la riqueza del país en sus distintas formas y sea cual fuere su titularidad está subordinada al interés general», y en el párrafo segundo se reconoce la iniciativa pública en la actividad económica llegándose a acordar la intervención de empresas cuando así lo exigiere el interés general. En todo caso, no hay riesgo de una interpretación constitucional en un sentido totalitario o colectivista, no sólo por los límites señalados sino por el principio de pluralismo y libertad que fundamenta el Estado social y democrático de Derecho de nuestra Constitución. Ahora bien, es indiscutible la potencialidad participativa del título VII y en especial del artículo 129 que puede justificar, si existe la voluntad política, la configuración de un verdadero sector de economía solidaria en el conjunto del sistema social y económico de nuestro país.

Es evidente que se exige un desarrollo normativo de los artículos constitucionales para que se adquieran verdaderos derechos subjetivos por los ciudadanos pero al tratar de la eficacia jurídico-formal de tales normas constitucionales algunos autores han señalado que si hubiera disposiciones restrictivas o prohibitivas de tal participación podría pensarse en un supuesto de posibles inconstitucionalidades. Es cierto que las normas sobre participación están vinculadas a los niveles de realización que en cada momento histórico llegan a alcanzarse. Ahora bien, tampoco puede afirmarse — han señalado los catedráticos de Derecho del Trabajo, José Vida Soria y Francisco Javier Prados de Reyes- que la evaluación de la actividad normativa relacionada con este precepto — artículo 129 de la Constitución- arroje un haber igual a la potencialidad que este artículo encierra en 
cualquiera de sus órdenes, tanto por la extensión de los sectores que enuncian como por la intensidad de los modelos de participación que pudiera diseñarse en cada uno de ellos ${ }^{2}$. Es más, estos autores, que insisten en los límites que establecen el modelo político económico concreto de la Constitución, el de Economía de mercado y propiedad privada, señalan que por debajo de dicho límite, sin embargo, se ofrecen extraordinarias posibilidades para la actuación política, tanto en la selección de los mecanismos de participación como en la determinación cualitativa de los mecanismos. Posibilidades que permiten una capacidad de adaptación no sólo a la propia ideología que en cada caso inspire la regulación positiva en esta materia, sino en las diversas exigencias que el proceso de renovación social exigen en un momento y ha de seguir planteando en el futuro ${ }^{3}$.

\section{A. La participación en la Seguridad Social y en otros órganos sobre calidad de la vida y bienestar general}

El párrafo primero del artículo 129 de la Constitución señala que «la ley establecerá la forma de participación de los interesados en la Seguridad Social y en la actividad de los organismos públicos cuya función afecte directamente a la calidad de la vida o el bienestar general». Estos «interesados» podrían entenderse que son los trabajadores, pero conectado con el artículo 41 de la Constitución, en donde se señala que los poderes públicos mantendrán un régimen público de Seguridad Social para todos los ciudadanos, hace que, en realidad, sean estos ciudadanos, en un sentido amplio, a los que podemos identificar como tales interesados. Por otra parte, la fórmula que a continuación se enuncia de organismos públicos cuya función afecte directamente a la calidad de la vida o al bienestar general es de tal amplitud, por afectar ciertamente a la vida humana en su plenitud, que no puede sustraerse a ningún miembro de la comunidad de este deseo de influir en órganos que tengan tan alta misión de bienestar colectivo. Ciertamente, nos encontraríamos ante una consecuencia en la vida económica y social del Estado social y democrático de Derecho cuyo desarrollo dependerá de las fuerzas políticas que predominen en el seno de los poderes públicos pero en un horizonte de un Estado altamente desarrollado ${ }^{4}$.

2 Vida Soria, José; Prados de Reyes, Francisco Javier (1988), «Comentarios al artículo 129», en Óscar Alzaga (coord.) Comentarios a las leyes políticas. Constitución española de 1978, Tomo IX. Edersa. Madrid, pp. 107 y ss.

3 Ibidem. P. 107.

${ }^{4}$ Cazorla, Luis M. (1980) «Comentario al artículo 129.2», en Garrido Falla, Fernando, Comentarios a la Constitución, Civitas, Madrid, pp. 1361-1371. 
Ello también implicaría un nuevo modelo de la Administración Pública en la que los ciudadanos mediante sorteo o elección pudieran estar presentes en los distintos órganos de gestión y de modo especial en aquellos que afectan al bienestar colectivo, para ejercer funciones de control y supervisión pero también para comprender la complejidad y dificultades de la gestión pública, lo que nos llevaría a un nuevo modelo de Administración Pública cooperativa, atravesado por este principio de participación ${ }^{5}$.

Una aplicación de tal norma fue la constitución del Consejo Económico y Social y también la Ley General de la Seguridad Social y sus decretos de desarrollo así como el Real Decreto 1/2007 que aprueba la Ley General de Consumidores y Usuarios en lo que afecta a esa participación en órganos relacionados con la calidad de vida o el bienestar general.

\section{B. La participación en la empresa y su dimensión comunitaria}

Al inicio del párrafo $2{ }^{\circ}$ del artículo 129 de la Constitución se indica que los poderes públicos promoverán eficazmente las diversas formas de participación en la empresa... Ciertamente es una redacción muy genérica y un tanto ambigua que permitiría diversas interpretaciones y alcances. La idea de que los poderes deben promover eficazmente esa participación en el seno de la empresa supone una obligación aunque mediante diversas formas. Cabría desde la simple información, hasta el control contable o formas de codecisión típicas de la cogestión en el capitalismo social.

En el caso español el Estatuto de los trabajadores, Ley 1/1995, se ha previsto la creación de delegados de personal y comités de empresa — en aquellas de más de 50 trabajadores - con competencias sobre información, consulta y control. Otras normas legales prevén el derecho de información de los representantes de los trabajadores en materia de contratación (Ley 2/1991) o sobre derechos de información y consulta de los trabajadores en las empresas y grupos de empresas de dimensión comunitaria (Ley 10/1997, modificada por la Ley 44/1999, y por el Real Decreto Legislativo 5/2000 por lo que se aprueba el texto refundido de Ley sobre Infracciones y Sanciones en el orden social). La jurisprudencia del Tribunal Constitucional ha reforzado esta interpretación a favor de la representación de interés colectivos (STC. 49/1988 de 22 de marzo).

5 Colomer Viadel, Antonio (2006), «Para una teoría de la Administración Pública cooperativa», en Antonio Colomer (coord.), La participación en las Administraciones Públicas ¿cooperación o enfrentamiento?, Editorial UPV. Valencia. 2006. Pp. 33-40. 
Cabrían, sin lugar a dudas, otras formas de participación que solo tímidamente se han intentado como la participación en beneficios. Si se justifican recortes salariales y todo tipo de ajustes en época de crisis, parece razonable, por una reciprocidad, que en época de bonanza empresarial los trabajadores vean también compensados sacrificios anteriores participando en los excedentes producidos.

Salvando siempre el sacrosanto modelo de libertad de empresa y propiedad privada que es su límite en la economía de mercado, sin embargo, autores como Jose Vida y Francisco Javier Prados de Reyes señalan que la política del legislador en esta materia tenía un propósito integracionista y no ajeno a cierta concepción comunitarista de la empresa. Y observan que aún no se obtiene el máximo de posibilidades que la formulación constitucional ofrece ${ }^{6}$.

En este sentido hubiera sido mucho más coherente con el espíritu participativo y comunitario de la empresa que se presume al constituyente, la tesis sobre la empresa integrada, de Montero de Burgos, que plantea una nueva formulación de la propiedad y del derecho a decidir y su fundamento, cuantificando el riesgo y la evolución del mismo en la empresa, mediante una dialéctica propiedad y poder que aborde en un sentido comunitario este problema social ${ }^{7}$.

En suma, podemos resumir, que la participación en la gestión por los trabajadores, en determinadas parcelas, respetando la titularidad de propiedad del empresario y el ejercicio de sus facultades, no ha tenido el desarrollo que potencialmente podía extraerse de la norma constitucional para convertir tal disposición y su desarrollo legislativo en una verdadera manifestación de la economía social.

\section{Cooperativas}

En el mismo artículo 129. 2, se continua indicando que esto mismo poderes públicos, que, como hemos visto, deben promover la participación en la empresa, también «fomentarán mediante una legislación adecuada las sociedades cooperativas». El constituyente apuesta por este modelo de la Economía Social y Solidaria como prioritario dando un mandato al legislador para que elabore esa legislación adecuada mediante una finalidad de fomento, y, por tanto, de crecimiento de estas sociedades cooperativas. Es coherente tal mandato - y ade-

${ }^{6}$ Op. cit., p. 114.

7 Montero de Burgos, José Luis (1990), Propiedad, Empresa y Sociedad: Nueva Alternativa, INAUCO, Editorial La Hora de Mañana, Madrid. 
lantado varias décadas - con una política de la propia Asamblea General de Naciones Unidas que, según la resolución número 62/128, de 29 de enero de 2008 , considera que es propicio y adecuado el apoyo a las cooperativas por que contribuyen al Desarrollo Social, erradicar la pobreza, generar empleo productivo y mayor integración social.

Al poco de aprobarse la Constitución se insistía por la doctrina en una interpretación expansiva de la legislación adecuada para ese fortalecimiento y desarrollo de las cooperativas. «Legislación adecuada equivale no a una sola ley idónea o pertinente, si no a un conjunto o cuerpo de leyes por las cuales se gobiernan convenientemente una materia determina... (lo que resulta de suma importancia) dada la tradicional articulación pluralista de la norma cooperativa en nuestro derecho, que se ha venido haciendo en dos grandes bloques a saber: la normas del régimen básico de carácter sustantivo y la normativo de fomento y protección que no es solo de tipo tributario» ${ }^{8}$.

En el ordenamiento jurídico español se aprobaron varias leyes generales de cooperativas, la última de ellas la Ley 27/1999 que contempla diferentes campos de actividad: Cooperativas de crédito, consumo, vivienda, trabajo, educación y enseñanza, que responden, por cierto, a satisfacer derechos y principios constitucionales también recogidos en la Constitución, mediante una decidida integración de los ciudadanos en distintos sectores de la actividad social y económica.

Un problema planteado es que si la Sociedad Cooperativa es la única sociedad mercantil regulada en este campo seria competencia exclusiva del Estado, de acuerdo con el artículo 149. 1. ${ }^{\circ}$ 6. ${ }^{a}$ de la Constitución, lo que cerraría el paso a las Leyes de Cooperativas de las Comunidades Autónomas. Ahora bien, las presiones de sectores nacionalistas hicieron que se considerara que esta materia no estaba explícitamente reservada al Estado y por tanto era posible la legislación Autonómica sobre la misma, pese a que puede afectar a la unidad de mercado. En este sentido y después de que prácticamente todas la Comunidades Autónomas hayan elaborados las suyas, el parlamento Catalán, el 18 de junio del 2015, acaba de aprobar una nueva Ley de Cooperativas de Cataluña que pretende ser más ágil y flexible, reduce de 3 a 2 el mínimo de socios para constituir una cooperativa, e introduce las categorías de socios temporales y socios colaboradores que solo aportan capital, lo que supone un riesgo al principio básico de igualdad democrática de todos los socios para configurar las decisiones colectivas.

8 Paz Canalejo, Narciso (1980), «La Constitución y la Cooperativas», en Documentación Administrativa, n. ${ }^{\circ} 186$, abril-junio-1980, p. 79. 
Lo que resulta evidente es que el constituyente plantea una política de estímulo mediante la legislación adecuada para la integración de los ciudadanos lo que supone introducir en el orden jurídico español un principio «pro societate cooperativa», y en este sentido se ha dicho que solo las cooperativas, las mutuas de seguro y previsión, las sociedades laborales, y algunas otras formas societarias mutualizantes, deberían beneficiarse de las ventajas de la aplicación de este principio «pro cooperativa» y no las otras formas societarias. Este principio «pro cooperativo» — señala Angélica Díaz de la Rosa- debería ser entendido como principio de empresa más favorecida, mediante un tratamiento más favorable, de acuerdo con el criterio de no tratar igual cuando la condición es desigual ${ }^{9}$.

Un problema que habría que abordar pero iría más allá de los límites de este artículo es si en la práctica y en la legislación, se están respetando los principios o valores cooperativos. La no finalidad de lucro, el fin social y solidario, las puertas abiertas, la igualdad democrática de los socios para la toma de decisiones, etc. Podemos apuntar que se ha dado una deriva mercantilista en bastantes casos, en el peor sentido de la expresión. Ya en ese tratamiento desigual de socios y su tipología en algunas legislaciones. Hemos puesto el ejemplo de la Ley Cooperativa de Cataluña, por ser la más reciente pero no única en este sentido. Así como unas experiencias de precipitadas cooperativas para salvar empleo, sin formación en los valores cooperativos de los que las constituyen, causas de muchos fracasos, tanto por arrojarse en manos de un gerente salvador cuando las cosas no empiezan a funcionar, al que se le otorgan plenos poderes en una especie de neodictadura cooperativa, cuanto por un éxito mercantil inesperado se fuerza la reconversión en sociedad anónima para cerrar esa puerta abierta cooperativa y monopolizar el beneficio en manos del primer grupo. En este sentido fue especialmente aleccionadora la tesis doctoral de la Profesora María Jesús Vara Miran$\mathrm{da}$, sobre las causas de los fracasos de las cooperativas de trabajo asociado en Madrid, que el Ministerio de Trabajo publicó con el título más suave de «las Cooperativas Industriales de Madrid» ${ }^{10}$.

9 Díaz de la Rosa, Angélica (2010), «Reflexiones a propósito del artículo 129. 2. ${ }^{\circ}$ de la Constitución española», Anuario Da Facultade de Dereito da Universidade da Coruña, n. ${ }^{\circ} 14$, pp. 311-324.

${ }^{10}$ La Profesora Vara Miranda de la Universidad Autónoma de Madrid, fue Secretaria del Consejo de Redacción de la Revista Iberoamericana de Autogestión y Acción Comunal del INAUCO. Al análisis de su obra y bajo el epígrafe la Conciencia Cooperativa dediqué un espacio en Colomer Viadel, Antonio, «Autogestión, Democracia y Cooperación para el Desarrollo», Acción Cultural Cristiana, Madrid 2002, p. 91. 


\section{El Acceso de los Trabajadores a la Propiedad de los Medios de Producción. La Economía de Participación y la Economía Social y Solidaria}

El último párrafo del artículo 129, como punto y seguido al de fomento a las Cooperativas, es el más rotundo y radical en un planteamiento que algunos han podido considerar casi revolucionario y, por supuesto, el fundamento para alzar una economía de participación generalizada como economía social y solidaria. El constituyente lo redactó del siguiente modo: «También establecerán (los poderes públicos) los medios que faciliten el acceso de los trabajadores a la propiedad de los medios de producción». Como ya se habían hecho referencias a las Cooperativas es evidente que se trata de nuevas formas de participación y de propiedad por los trabajadores, ya sea por el accionario obrero o la propiedad mobiliaria de acciones típicas del capitalismo popular, o algo más allá.

Alguna desconfianza y susceptibilidad se creó tanto en los sectores conservadores políticos y empresariales como en la misma doctrina. Los citados colegas Vida y Reyes escribieron: «esta expresión puede sobrevalorarse políticamente tratando de localizar en ella la designación de sistema socio-económico de carácter más o menos colectivista» ${ }^{11}$. Alertan sobre los límites ya citados de la propiedad privada y la herencia, la libertad de empresa y la economía de mercado, y a pesar de la función social de esa propiedad. Ahora bien, reconocen que esa fórmula, fundamentalmente de carácter económico y financiero para que se contribuya a este acceso a la propiedad por los trabajadores tiene un matiz político de carácter integrador por el cual las clases trabajadoras serían los sujetos destinatarios de estas opciones del ahorro privado e inversor, aunque a través de los mecanismos de accionario obrero y otros modelos limitados de co-gestión.

Debo señalar que el concepto de economía de participación que puede definir este espacio de la constitución economía y tiene su justificación en la importancia transversal del concepto de participación en nuestra constitución de 1978, fue acuñado por primera vez por el profesor Jaroslav Vanek, a comienzos de los años $70^{12}$.

Conviene decir que el profesor Vanek identifica esta economía de participación con una economía de autogestión en la que la clave principal es que los trabajadores participan en la dirección decisiva de la empresa.

11 Op. cit., p. 116.

12 Jaroslav VANEK, The participatory economy. And evolutionary bypothesis and a strategy for development, Cornell University Press, Ithaca, New York, 1971. Existe una traducción al español, La Economia de Participación, Instituto de Estudios Peruanos, Lima, 1971. El 20 de noviembre de 2017 fallecio en Ithaca, Nueva York, el Profesor Vanek (q.e.p.d.). 
En nuestro caso nunca se pretendió tal transformación pero si se introdujeron algunos otros modelos empresariales de participación. Uno de los que más éxito ha tenido ha sido el de la sociedad laboral, que en su origen fue una experiencia piloto empresarial como Sociedad Anónima Laboral, ensayada en los transportes urbanos de Valencia (Saltuv) en 1964, y que fue imitada en este y otros sectores, desde entonces con gran profusión, a pesar de que la primera ley que las reguló fue de 1986.

Como fundador y director de la Escuela de Formación Empresarial y Comunitaria de Saltuv entre 1973 y 1976, viví esta experiencia en la que la Fundacion Fultuv tenía la mayoría de acciones de la Sociedad Anónima Laboral y otorgaba a cada trabajador dos acciones y se las recompraba si abandonaba la empresa. Era un verdadero instrumento de equilibrio y estabilidad del capital, pero hay que decir que la elección de la junta de gobierno de Fultuv era totalmente democrática e igualitaria ya que intervienen en ella todos los trabajadores que tenían el mismo número de acciones, dos cada uno ${ }^{13}$.

Conviene contrastar este espíritu democrático e igualitario que responde a la idea de que la SAL tenía un corazón cooperativo en un cuerpo de sociedad anónima, con la regulación legislativa posterior. Así, en la ley de sociedades laborales, Ley 4/1997, de 24 de marzo, en su artículo 5.3 se señala que ninguno de los socios podrá tener acciones o participaciones sociales que representen más de la tercera parte del capital social. Es decir, en sentido contrario, que algunos socios podrán tener prácticamente el $33 \%$ de ese capital. Y en el caso de que en esas sociedad laborales participen el Estado, las Comunidades Autónomas, las Entidades Locales o sus sociedades públicas se podrá llegar al casi el límite del $50 \%$ del capital social, por esas entidades públicas.

Es evidente que esta regulación esta en oposición al mandato a los poderes públicos para que faciliten el acceso a los trabajadores — se entiende que a todos - a la propiedad de los medios de producción, y choca también con el principio democrático igualitario, de inspiración cooperativa. Por ello entiendo que tales normas legislativas hubieran podido ser causa de un recurso de Inconstitucional por vulneración del artículo 129.2 de nuestra Constitución. En la nueva ley 44/2015, de 14 de octubre, de Sociedades Laborales y Participadas (BOE, 15-10-2015), en su Preámbulo se afirma que las Sociedades Laborales son

13 Colomer Viadel, Antonio (1975), «A Spanish System of self managmet enterprise: the labour anonymons society of urban transport of Valencia», Comunicación a la II Conferencia Internacional de Autogestión, Cornell University, Ithaca, New York, junio 1975. Un análisis más actual en COLOMER VIADEL, Antonio (2017) «SALTUV: La primera Sociedad Anónima Laboral» en Fajardo, Gemma y Senent, Maria José; Participación de los trabajadores y Sociedad Laboral, Tirant lo Blanch, València. 
sociedades de capital... Y esa situación exige una adecuación de la Ley de Sociedades Laborales al nuevo marco normativo y una sistematización de sus normas más acorde con lo establecido en la Ley de Sociedad de Capital... Aunque se reconoce que las Sociedades Laborales por sus fines son entidades de la economía social y, por tanto, deben ser acreedoras de políticas de promoción.

Otro problema es si se han facilitado los medios de organización federalista para alcanzar un punto de masa crítica compleja que permitiera una cierta invulnerabilidad de este tipo de empresas y organizaciones - Cooperativas, Sociedad Laborales, Mutuas, Empresas Comunitarias, etc. - articuladas en un verdadero sector económico. Y fundamentalmente si se han dispuesto el acceso en condiciones más favorables a los sectores financieros, especialmente del ahorro popular, que actuara como verdadera palanca de crecimiento de este sector.

Una ocasión que parecía la idónea para definitivamente aplicar en la práctica toda la potencial de estos mandatos constitucionales que estamos citando fue la aprobación de la llamada Ley de Economía Social (Ley 5/2011, de 29 de marzo). El objetivo básico de la ley señala su preámbulo, es configurar un marco jurídico que suponga el reconocimiento y mejor visibilidad de la economía social. Así como la promoción, estímulo y desarrollo de la las entidades de la economía social y de sus organizaciones representativas. Forman parte de acuerdo con el artículo 5 de la Economía Social, Cooperativas, Mutuales, Fundaciones y Asociaciones, Sociedades Laborales, las Empresas de Inserción, lo centros especiales de empleo, las Cofradías de Pescadores, las Sociedades Agrarias de Transformación y la entidades singulares que se rijan por los principios orientadores de esta ley. En el artículo anterior, el n. ${ }^{\circ} 4$ se fijan como tales principios los de:

a) Primacía de las personas y los del fin social sobre el capital.

b) Aplicación de los resultados obtenido de la actividad económica, principalmente en función del trabajo aportado y servicio o actividad realizada por las socios y socios.

c) Promoción de la solidaridad interna y con la sociedad...

d) Independencia respecto a los poderes públicos

¿Y cuáles son los instrumentos que se ponen al servicio de tal organización y de tales principios? Al llegar aquí conviene establecer un paralelismo con una ley semejante, la Ley de Organización y Fomento de la Economía Solidaria, de Colombia (Ley n. ${ }^{\circ} 454$, de 4 de agosto de 1998).

La Ley española en su artículo 9 establece el Consejo para el Fomento de la Economía Social, como órgano asesor y consultivo, a través del Ministerio de Trabajo, de la Administración general del Estado y para ello informar la elaboración de proyectos de ley sobre Economía Social, informar de programas de 
desarrollo, realizan estudios e informes, velan por la promoción y el respeto de los principios orientadores de la ley.

Este Consejo está compuesto por representante de la Administración General del Estado, de la administraciones autonómicas, de la asociación de entidades locales, de las confederaciones intersectoriales representativas, así como de entidades sectoriales mayoritarias de la economía social. La presidencia de este Consejo corresponderá a la persona titular de la Secretaria de Estado de empleo.

En el artículo 8 se regula las materias de fomento y difusión de la economía social. En primer lugar, como tarea de interés general, la promoción, estímulo y desarrollo de las entidades de la economía social y de sus organizaciones representativas. Y para ello los poderes públicos tendrá como objetivos de sus políticas de promoción — lo reproducimos de forma simplificada y esquemática: a) Simplificar los trámites administrativos; b) facilitar las diversas iniciativas de economía social; c) Promover los principios y valores de la economía social; d) promocionar la formación y readaptación profesional en este ámbito; e) facilitar el acceso a los procesos de innovación tecnológica...; f) Crear un entorno que fomente el desarrollo de estas iniciativas sociales y económicas; g) Involucrar a las entidades de entidades de economía sociales en las políticas activas de empleo...; h) Introducir referencias a la economía social en los planes de estudios...; i) Fomentar el desarrollo de la economía social en áreas como el desarrollo rural, la dependencia y la integración social.

Solo notamos la ausencia de un pequeño detalle: ¿Cómo se financia este nuevo sector y las múltiples empresas de economía social a crear?

Y aquí viene el interés del análisis comparativo con la citada Ley colombiana de Organización y Fomento de la Economía Solidaria.

En el artículo 1 de esta Ley se señala como objeto reconocer dentro de la economía nacional un sector diferenciado... denominado economía solidaria; en su artículo 4 que recoge los principios de esa economía se incluyen, entre otros, los siguientes:

1. Primacía del trabajo sobre el capital.

2. Primacía del trabajo asociado sobre el trabajo asalariado.

3. Primacía de la dinámica de comunión sobre la dinámica de conflicto.

4. Democracia participativa y autogestionaria.

5. Propiedad social comunitaria de los medios de producción.

Los componentes de este sector económico, según el artículo 5 serían las empresas cooperativas, los fondos de empleados, las asociaciones mutualistas, las cajas de compensación familiar, las empresas de trabajo exclusivamente familiar, las fundaciones y asociaciones inspiradas en los principios de esta ley, 
y en general las empresas gestionadas por los trabajadores que se constituyan en comunidades de trabajo dedicadas a tareas prioritarias en los planes nacionales de desarrollo.

Y los instrumentos para poder realizar estos fines son los siguientes:

La creación del Consejo Nacional de Economía Solidaria (CONES), con plena autonomía administrativa y funcional que será el ente coordinador del sector a nivel nacional en cuanto a políticas y estrategias para su propio desarrollo; Representará al sector ante el Estado y la Sociedad y a nivel nacional e internacional; Elaborará y propondrá el plan nacional de desarrollo del sector de la economía solidaria, entre otras tareas (Capítulo II artículo 6).

En el Capítulo III, artículo 10, se regula el Fondo para el Fomento de la Economía Solidaria (FONES), como entidad privada sin fines de lucro, con Personería Jurídica propio y patrimonio independiente, cuyo objeto social es de promover el desarrollo de las diferentes formas de asociación del sector de la economía solidaria, mediante el financiamiento de sus diferentes actividades productivas. Según el artículo 11 los miembros del Fondo serán los bancos cooperativos y demás entidades financieras del sector solidario de la economía y de las demás que no siendo financieras quieran suscribir aportes, y el Estado colombiano. Este Fondo celebrará operaciones de crédito, redescontar las operaciones, captara ahorro mediante la emisión de cualquier clase de título según la ley y brindaría asesoría técnica para el diseño y ejecución de proyecto específicos financiado por el FONES a través de sus miembros.

Conviene destacar la composición de la junta directiva del FONES, que la preside el presidente del CONES, y la integran tres representantes de los miembros elegido por la Asamblea, un representante del gobierno nacional, y dos representantes de los demás subsectores que sin ser miembros del FONES son parte activa del Consejo Nacional de Economía Solidaria.

Asimismo en el Capítulo IV, artículo 18, se crea el Fondo de Garantías de Economía Solidaria, adscrito al FONES, destinado a garantizar los proyectos de inversión de las empresas de producción y trabajo asociado del sector que así lo requiera.

La Ley, en su Capítulo V, establece una Cámara de Registro, adscrita al CONES, tanto para registrar las Instituciones de Economía Solidaria como para certificar sobre los actos y documentos relacionados con este registro ${ }^{14}$.

Nos encontramos, pues con una verdadera estructura y sus instrumentos operativos para constituir un sector capaz de equipararse y competir con los

14 Colomer Viadel, Antonio, «Autogestión, Democracia y Cooperación para el Desarrollo», op. cit., pp. 100-108. 
sectores público y privado ya sean de acciones, como individual. Es cierto que el Gobierno colombiano nada más aprobarse la Ley decidió, por motivos presupuestarios, dejar en suspenso el Fondo para el Fomento de la Economía Solidaria, con lo que dejaba inoperante la aplicación práctica de esta Ley, pero su texto sigue en vigor y supone una herramienta útil, autónoma y diferenciada para el crecimiento del sector de la Economía Solidaria.

En el caso español, como hemos visto, y a pesar del mandato constitucional y su potencialidad participativa y solidaria, no se ha pasado de la simple retórica, sin articular las herramientas precisas para construir ese sector de la Economía Social y Solidaria.

El marco constitucional existe y el posible desarrollo de ese sector queda pendiente para lo que se exige una voluntad política y conciencia en los que vayan aplicar tales modelos en la práctica. En ningún caso la construcción supondría un peligro para la propiedad privada individual o por acciones, sino que sería entrar en ese principio de competencia estimulante en el mercado de una Economía Mixta en la que el sector solidario no tuviera una radical desigualdad respecto a los otros sectores.

Title:

Constitutional regulation of the participation of workers in the economy and in the companies.

\section{Summary:}

Preliminary note. 1. Introduction. 2. The economic constitution. A. Participation in Social Security and other bodies on quality of life and overall well-being. B. Participation in the company and its community dimension. C. Cooperatives. D. The access of workers to the ownership of the means of production. The participation economy and the Social and solidarity economy.

\section{Resumen:}

En el texto de la Constitución española de 1978, se opta por un modelo participativo, que se refleja en los artículos 7 y 9, en el título VII (Economía y Hacienda) y, en particular, el artículo 129 que parece contener un programa revolucionario en relación con la economía y la 
empresa y el acceso de los trabajadores a la propiedad. Sin embargo, no ha existido la voluntad política de desarrollar toda la potencialidad de la Constitución. Incluso se ha disminuido la tendencia participativa, especialmente en el campo social y económico.

\section{Abstract:}

The Spanish Constitution of 1978 opt for a participatory model, which is reflected in articles 7 and 9, in title VII (Economy and Finance) and, in particular, article 129 which seems to contain a revolutionary programme for the Economy and the companies, and the workers access to the property. However, there has been no political will to develop the full potential of the Constitution. Even declined the participatory trend, especially in the social and economic field.

\section{Palabras clave:}

Constitución económica, Economía social y solidaria; Economía de participación.

Key words:

Economic Constitution; Social and solidarity economy; participation economy. 